\title{
Fibrolipoma of the Floor of the Mouth - Report of a Rare Case and Review of the Literature
}

\author{
K. S. Vinod, ${ }^{1}$ Anitha, ${ }^{2}$ Shweta Hegde, ${ }^{3}$ M. Nagraj, ${ }^{4}$ Harsimran Kaur, ${ }^{5}$ and G. C. Shivakumar ${ }^{6}$ \\ Departments of ${ }^{1}$ Oral Pathology and Microbiology, ${ }^{2}$ Periodontics, ${ }^{3}$ Oral Medicine and Radiology, \\ ${ }^{4}$ Oral and Maxillofacial Surgery, Triveni Instisute of Dental Sciences, Hospital and Research Centre, Bodri, Bilaspur Dist., \\ Chhattisgarh State, India, \\ ${ }^{5}$ Department of Pedodontics, Kothiwal Dental College and Research Centre, Moradabad Dist., U. P. State, India \\ ${ }^{6}$ Department of Oral Medicine \& Radiology, BBD College of Dental Sciences, Faizabad Road, Lucknow, India
}

\section{Article History}

Received 24 November 2012

Accepted 29 January 2013

Keywords:

fibrolipoma, oral fibrolipoma, floor of

the mouth, ultrasonography

\begin{abstract}
Lipomas are the most common soft tissue tumors of mesenchymal origin. These tumors constitute about $20 \%$ of cases involving the head and neck region and $1-4 \%$ of those affecting the oral cavity, predominantly affecting the buccal mucosa, floor of mouth and tongue. Fibrolipoma is a rare histological variant of lipoma with a much lower incidence in the oral cavity. We report herein a case with large sublingual fibrolipoma along with a review of the literature for this tumor.
\end{abstract}

\section{Introduction}

Lipomas are the most common benign tumors of fat tissue in adulthood (1). A relatively rare intraoral tumor, lipoma occurs with considerable frequency in other areas, particularly in the subcutaneous tissue of the neck (2).

About $20 \%$ of cancers in the head and neck region are lipomas, whereas oral lipomas comprise only $1-4 \%$ of cases. These usually present as painless, well-circumscribed, slowgrowing submucosal mass or superficial lesions, mainly in the buccal mucosa (3).

Fibrolipomas belong to the family of fat-containing lesions and are benign variants of lipoma characterized by the presence of adipose tissue and abundant amounts of fibrous tissue. They are well-separated from the surrounding tissues and usually occur in adults (4). These lesions may have a broad base or may be pedunculated (5).

\section{Case report}

A 55-year-old man reported to the Department of Oral Medicine and Radiology with an 8-year history of swelling in the floor of the mouth. He also complained of difficulty with

\section{Correspondence to :}

Dr. Vinod. K.S.

E-mail : shiva21375@gmail.com drvinodks09@gmail.com mastication and speech. The lesion reportedly started as a small swelling about $1 \mathrm{~cm}$ in diameter, gradually increasing to the present size of about $6 \times 5 \mathrm{~cm}$. On clinical examination, a sessile swelling was seen in the floor of the mouth, with part attached to the base of the tongue. This dome-shaped lesion caused elevation of the tongue. On palpation, the swelling was non-tender, soft and mobile. The lesion was not associated with any kind of irritation, injury, ulceration or secondary infection. The color of the mucosa over the lesion also appeared normal (Fig.1).

Ultrasonography (US) revealed a sublingual mass measuring approximately $4.1 \times 3.5 \mathrm{~cm}$ in the sublingual region. The mass was cystic with coarse internal echoes, appearing as a solid echogenic lesion. The borders were well defined. The deeper part could not be evaluated well because of poor penetration of ultrasound due to extension of the lesion into deeper areas. For this reason, US underestimated the size of the mass. These findings of US were suggestive of sublingual dermoid, lipoma or ranula (Figs. 2, 3).

Incisional biopsy was performed and the specimen underwent histopathological examination, revealing a tumor mass composed of a collection of mature fat cells admixed with fibrous tissue, with a peripheral fibrous capsule. The tumor showed the classical findings of adipocytes admixed 


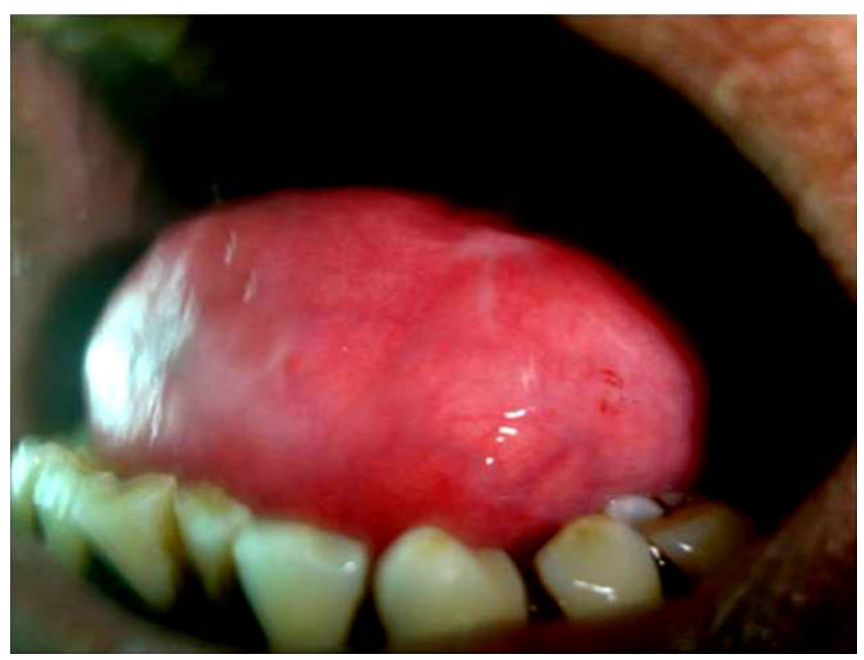

Fig.1 Intraoral photograph.

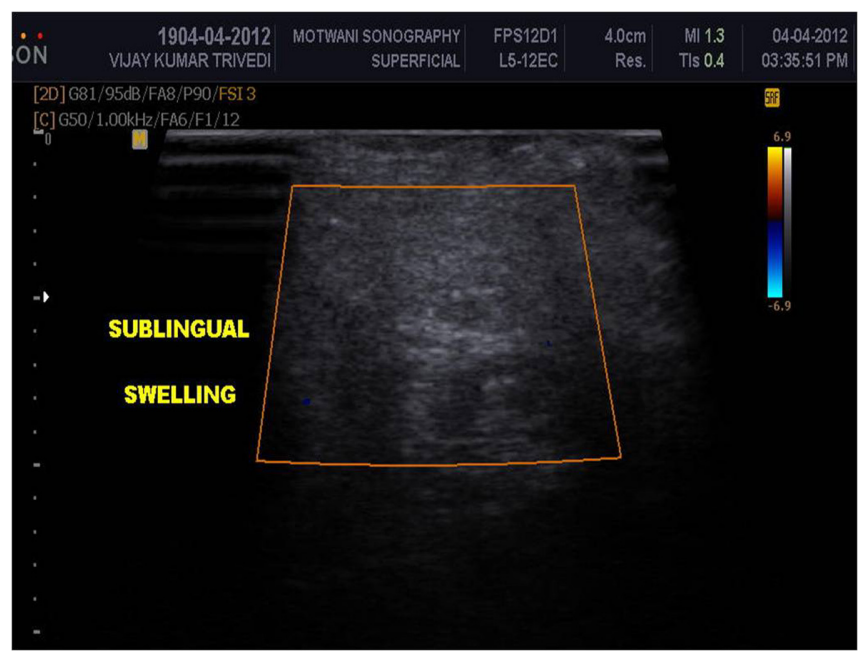

Fig.2 Ultrasonography

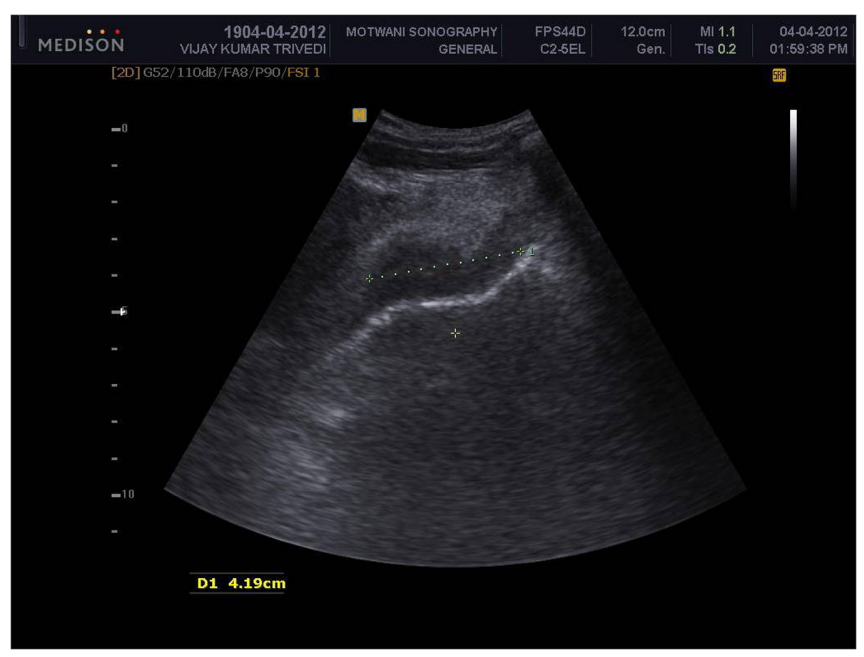

Fig.3 Ultrasonography

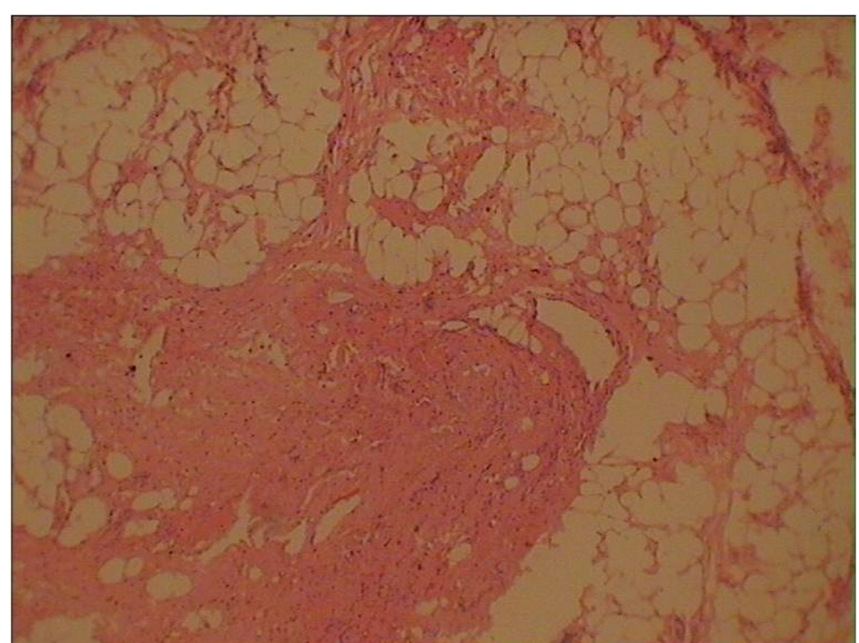

Fig.4 Histopathological examination of incisional biopsy.

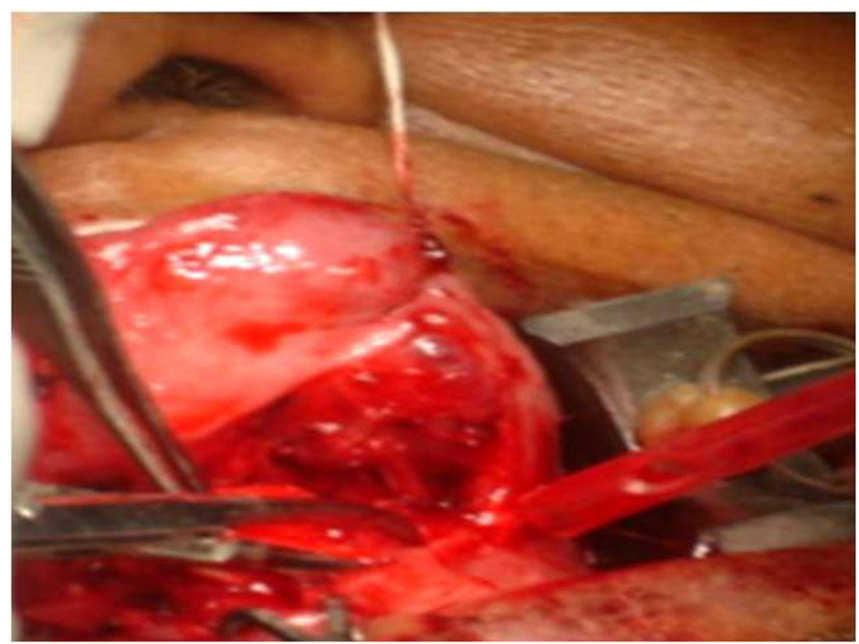

Fig.5 Surgical photograph.

with bundles of collagen fibers. No inflammatory reaction was noticed in any section of the tumor, nor was the fibrous component associated with irritation. Fibrolipoma was diagnosed (Fig.4).

Complete surgical excision of the tumor was recommended. After the results of routine blood investigations were found to be within normal limits, the patient was taken up for surgery (Fig.5). Because of the location and considering the size of the tumor, surgery was performed under general anesthesia through nasoendotracheal intubation. The excised tissue (Fig.6) was again observed microscopically, revealing fibrolipoma of the incisional biopsy tissue (Fig.7). This was in line with and supported the clinical picture described above and confirmed typical fibrolipoma. The patient was discharged after 2 days. Sutures were removed 


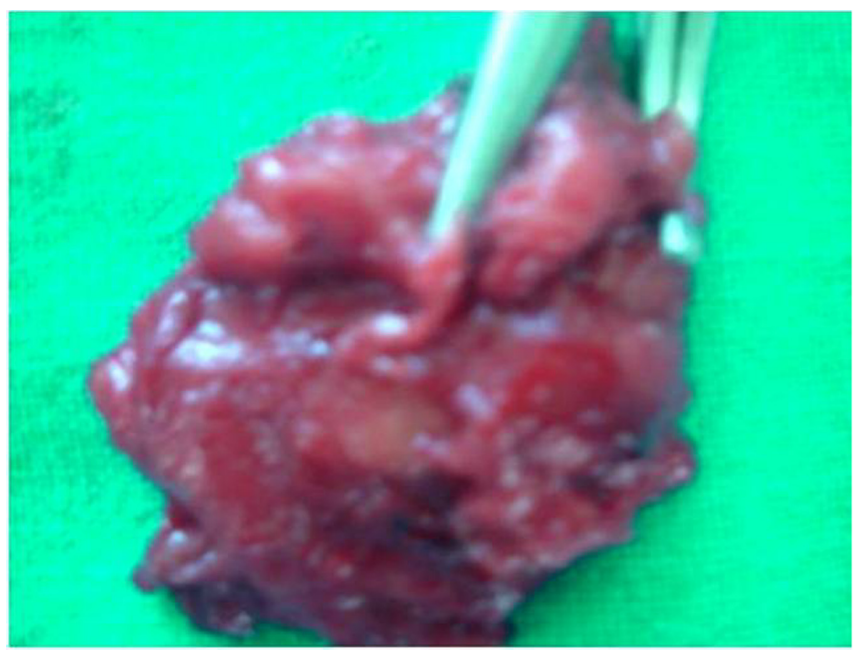

Fig.6 Surgical specimen.

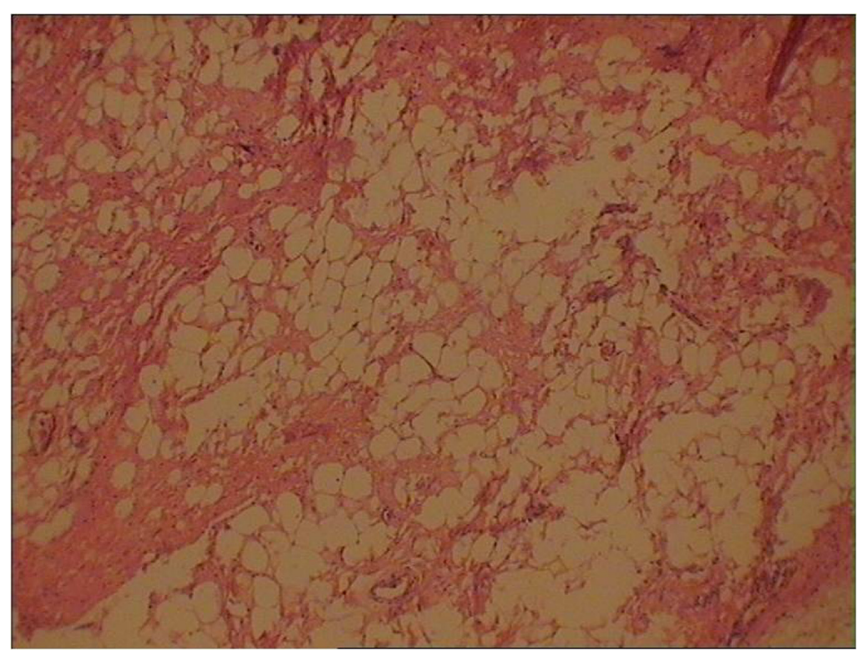

Fig.7 Histopathological examination of the excisional biopsy specimen.

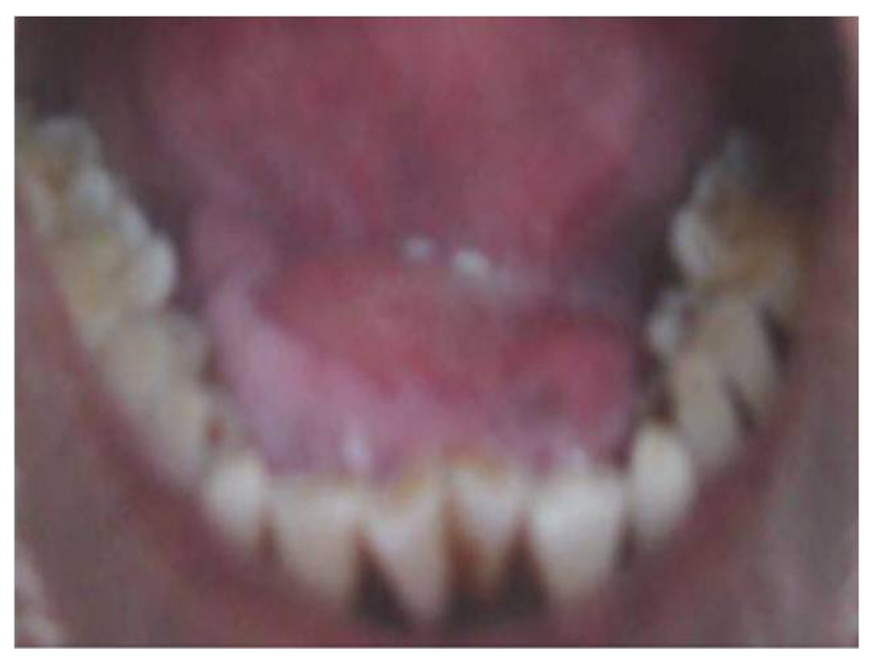

Fig. 8 Post-surgical photograph after 7 days, and healing was uneventful (Fig.8). The patient is under regular follow-up and no evidence of recurrence has been seen as of 1 year postoperatively.

\section{Discussion}

The first description of an oral lesion was provided in 1848 by Roux in a review of alveolar masses, referred to as "yellow epulis". Intraorally, a prevalence of only $1 / 5,000$ adults has been reported (2).

The etiology of lipoma is unknown. Possible causes may include trauma, infection, chronic irritation and hormone alterations. In some cases of lipoma, rearrangement of the 12q, 13q, 6p chromosomes has been observed (2).

Lipomas present as slow-growing asymptomatic lesions with yellowish coloration and a soft, doughy feel, arising in the buccal mucosa, floor of the mouth and tongue, generally in the fourth or fifth decades of life and with no gender predilection (1, 6-8).

Fibrolipoma is a benign tumor that rarely occurs in the oral and maxillofacial region, and is classified as a variant of conventional lipoma by the World Health Organzation (9). The tumor is reportedly more frequent in the buccal mucosa and buccal vestibule, and also shows a slight predominance in females $(10,11)$.

In the present case, the male patient showed the tumor in the floor of the mouth, a rare site for fibrolipomas in the oral cavity.

Infrequently, lipomas are large, intramuscular, and poorly circumscribed (1). Lipomas usually measure around a few millimeters to centimeters $(1,2)$. In 2003, Fregnani et al. collected several cases and diagnosed lipoma in $45.7 \%$ and fibrolipoma in $39.1 \%(6)$.

Fibrolipomas are one of the giant lipomatous tumors (defined as $>5 \mathrm{~cm}$ in diameter), and have reportedly been seen in the esophagus, intestinal mesentery, pancreas and parapharyngeal region (6). In the present case, the tumor measured around $6 \times 5 \times 3 \mathrm{~cm}$ in size, and such larger fibrolipomas are rarely reported, especially in the floor of the mouth.

Occasionally, superficial intra-oral lipomas can be diagnosed clinically, based on palpation and demonstration of a yellow hue (12). Deep-seated lipomas, however, are often indistinguishable from other mesenchymal tumors (13). In some cases, oral soft-tissue lipomas can present as a fluctuant nodule(14). Speech and mastication problems can also arise due to the location of the lipoma. The present case 
showed similar features, so lesions such as oral dermoid cyst, ranula, pleomorphic adenoma, oral lymphoepithelial cyst, granular cell tumor, neurofibroma, and traumatic fibroma had to be considered in the differential diagnosis ( 1 , 15-18).

Histologically, lipomas are classified as simple lipoma or variants such as fibrolipoma, spindle cell lipoma, intramuscular or infiltrating lipoma, angiolipoma, salivary gland lipoma (sialolipoma), pleomorphic lipoma, myxoid or atypical lipoma (9).

The microscopic appearance of a well-encapsulated mass of mature adipocytes is diagnostic of conventional lipoma, whereas fibrolipomas show blending of fibrous tissue with adipocytes $(1,19,20)$. In our case, tumor areas comprised typical fibrolipomatous tissue with a peripheral capsule comprising fibrous connective tissue.

Fibrolipoma has been suggested to arise from the maturation of lipoblastomatosis, which is an infiltrative type of benign neoplasm with lobules of immature fat cells separated by connective tissue septa and areas of loose myxoid matrix. Further, maturation of both adipose and fibrous tissues result in mature strands of collagen separating fat cells into lobules (21).

Fibrolipoma should be differentiated from spindle cell lipoma, which will display spindle cells against a mucinous/ fibrous background. On occasion, fibrolipoma can be confused with a herniated buccal fat pad, but the characteristics of a well-circumscribed lesion with a lack of any history of trauma can help in differentiation(22).

Lipomas are usually cured by simple excision (1). The risk of recurrence is reduced by wide surgical excision (22). These tumors can be life-threatening due to obstruction of the upper airway by virtue of the size of the lesion, and death due to sudden asphyxia has been reported in a case of esophageal fibrolipoma (10). Infiltrating lipomas are difficult to extirpate and liable to recur (23).

\section{Conclusion}

Fibrolipomas are uncommon tumors of the oral cavity and are even more rarely reported in the floor of the mouth. The many other types of pathological lesions occurring in this area pose a difficulty in diagnosis, and support of diagnostic imaging like US was needed in this case. Early treatment is advisable for tumors at this site, to avoid interference with the important functions of respiration, mastication and deglutition. Surgical removal from this location complicates this task compared to similar lesions in other areas, necessitating highly precise surgical excision to minimize the risk of recurrence.

\section{References}

1. Kumar V, Abbas AK, Fausto N, Aster J: Robbins, Cotran Pathologic basis of disease. 8th ed., Elsevier, 2012, p.1249.

2. Shafer WG, Hine MK, Levy BM: Shafer's textbook of oral pathology. 6th ed., Mosby Saunders, 2009, p.137-139.

3. Manjaunatha BS, Pateel GS, Shah V: Oral fibrolipoma -a rare histological entity: report of 3 cases and review of literature. J Dent (Tehran), 7: 226-231, 2010.

4. Janas A, Grzesiak-Janas G. The rare occurrence of fibrolipomas. Otolaryngol Pol, 59: 895-898, 2005.

5. Grakom GS, Brannon RB, Houston GD: Fibrolipoma of the gingiva: a case report. J Periodontol, 59: 118-120, 1988.

6. Fregnani ER, Pires FR, Falzoni R, Lopes MA, Vargas PA: Lipomas of the oral cavity: clinical findings, histological classification and proliferative activity of 46 cases. Int J Oral Maxillofac Surg, 32: 49-53, 2003.

7. Benign lipomatous tumors. In: Weiss SW, Goldblum JR, editors. Enzinger and Weiss's soft tissue tumors. 4th ed., St. Louis: Missouri; Mosby, 2001, p.571-639.

8. Lucas R B. Pathology of tumors of the oral tissue. 4th ed., Edinburgh: Churchill Livingstone, 1984, p.176-179.

9. Fletcher CDM, Unni KK, Mertens F: Adipocytic tumors. In: Pathology and genetics: tumours of soft tissue and bone. World Health Organization Classification of Tumours. Lyon: IARC Press, 2002, p.9-46.

10. Gupta S, Patak S: Fibroma of buccal mucosa - a case report. J Ind Dent Assoc, 5: 737-738, 2011.

11. Epivatianos A, Markopolos AK, Papanayotou P: Benign tumors of adipose tissues of oral cavity: a clinicopathological study of 13 cases. J Oral Maxilofac Surg, 58: 1113-1117, 2000.

12. Zhong L, Zhao S, Chen G, Ping F: Ultrasonic appearance of lipoma in the oral and maxillofacial region. Oral Surg Oral Med Oral Pathol Radiol Endod, 98: 738-740, 2004.

13. Philiponea E, Yoona AJ, Zegarellia D: Large fibro-lipoma of tongue removed via punch biopsy: an intra-oral application of the narrow hole extrusion technique (NHET). J Orofac Sci, 2: 41-43, 2010.

14. Tan MS, Singh B: Difficulties in diagnosing lesions in the floor of the mouth-report of two rare cases. Ann Acad Med Singapore, 33: 72-76, 2004.

15. Regezzi JA, Scubba JJ, Jordan RCK: Oral pathology clinical pathologic correlations. Elsevier, 4th ed., 2003, p.180-181.

16. Bandeca MC, de Padua JM, Nadalin MR, Ozorio JE, SilvaSousa YT, Cruz Perez DE: Oral soft tissue lipomas: a case series. J Can Dent Assoc, 73: 431-434, 2007.

17. Adoga AA, Nimkur TL, Manasseh AN, Echejoh GO: Buccal 
soft tissue lipoma in an adult Nigerian: a case report and literature review. J Med Case Reports, 2: 382, 2008.

18. Lawoyin JO, Akande OO, Kolude B, Agbaje JO: Lipoma of the oral cavity: clinicopathological review of seven cases from Ibadan. Niger J Med, 10: 189-191, 2001.

19. Coban YK, Coskun A. Giant fibrolipoma mimicking abdominal lipodystrophy. Indian J Plast Surg, 41: 97-98, 2008.

20. Enzinger FM, Weiss SW: Soft tissue tumors. 2nd ed., St. Louis; Mosby; 1988, p.303-400.
21. Greer RO, Richardson JF: The nature of lipomas and their significance in the oral cavity. A review and report of cases. Oral Surg Oral Med Oral Pathol, 36: 551-557, 1973.

22. Rossa J, ediyor: Ackerman's surgical pathology. Vol.2. 8th ed., St. Louis, Mosby; 1996, p.2053-2054.

23. Chidzonga MM, Mahomva L, Marimo C. Gigantic tongue lipoma: a case report. Med Oral Patol Oral Cir Bucal, 11: 437439, 2006. 